\title{
ON THE DEVELOPMENT OF THE BLOOD-VESSELS OF THE BRAIN IN THE HUMAN EMBRYO.
}

\author{
BY \\ FRANKLIN P. MALL. \\ From the Anatomical Laboratory of the Johns Hopkins University. \\ With 3 Double Plates and 4 Text Figures.
}

During the past year, while studying sections through the heads of the embryos in the collection at this laboratory, it was noticed that in some of the specimens the blood-vessels were unusually well marked, for they were well distended with blood. This natural injection made it possible to reconstruct the blood-vessels in a satisfactory manner down to the capillaries. At the same time I obtained from Mr. Brödel a number of embryos' brains in which the arteries had been injected with Prussian blue, which, together with numerous embryo pigs injected alive or immediately after death, form the basis of this study.

TABLE OF EMBRYOS STUDIED.

\begin{tabular}{|c|c|c|c|c|}
\hline Number. & $\begin{array}{l}\text { Length } \\
\text { in mm. }\end{array}$ & $\begin{array}{l}\text { Thlckness of } \\
\text { Section in } \mu \text {. }\end{array}$ & $\begin{array}{l}\text { Direction of } \\
\text { Section. }\end{array}$ & From Whom Obtained. \\
\hline $\begin{array}{r}10 \tilde{3} \\
109 \\
144 \\
74 \\
145 \\
225 \\
237 \\
233 \\
234 \mathbf{b} \\
\ldots 39 \\
234 \\
233 \\
236\end{array}$ & $\begin{array}{r}7 \\
9 \\
11 \\
14 \\
19 \\
33 \\
46 \\
48 \\
59 \\
65 \\
80 \\
80 \\
90 \\
92\end{array}$ & $\begin{array}{l}15 \\
20 \\
20 \\
40 \\
40 \\
50 \\
50 \\
\cdots \\
\because \\
\because \\
\because \\
\ddot{50} \\
\because \\
\because .\end{array}$ & $\begin{array}{c}\text { Trangverse } \\
\text { Sagittal } \\
\text { ". } \\
\text { Injected } \\
\text { ". } \\
\text { ". } \\
\text { Transverse } \\
\text { Injected }\end{array}$ & $\begin{array}{l}\text { Dr. C. O. Miller. } \\
\text { Dr. D. S. Lamb. } \\
\text { Dr. Harvey Cushing. } \\
\text { Dr. Watson. } \\
\text { Dr. Irving Miller. } \\
\text { Dr. W: T. Watson. } \\
\text { Dr. Wegefarth. (Brödel Collection). " " } \\
\text { Dr. Todd. } \\
\text { Dr. Linthicum. } \\
\text { Brodel Collection. } \\
\text { Brodel Collection. } \\
\text { Dr. Ashby } \\
\text { Dr. Smart } \\
\text { Dr. Wilson }\end{array}$ \\
\hline
\end{tabular}

The blood-vessels of five human embryos were reconstructed from serial sections, and eight older embryos which had been injected were dissected. The brains of pigs which had been injected with India ink proved to be of great value to control the studies of the human. It is quite easy to make single or even double injections of young embryos by injecting them either before or after death, or both. In case India ink is injected into the liver of a live pig with a hypodermic syringe, the AMERICAN JOdRNAL OF ANATOMT.-VOL. IV. 
fluid is taken up by the heart and is pumped through the arterial system. When all the arteries are full the beat of the heart may be arrested by cooling the embryo. A second injection into the liver with a different fiuid (and for this purpose I usually employed aqueous Prussian blue) fills the entire venous system. More frequently single injections were made of the arteries or of the veins by injecting India ink into the liver either before or after the heart had ceased to beat. India ink, being resistant, is preferred, for embryos injected with it can be hardened in alcohol and cleared in a one per cent solution of caustic potash and preserved in glycerine. Such specimens are perfectly transparent, showing the arrangement of the vessels beautifully and their relation to the structures within the head. Sagittal sections of whole embryos are also very valuable for study, for the half brain is easily peeled out, leaving the injected membranes intact within the head.

It is difficult to make complete injections of the veins of the head in dead embryos without extravasations into the arachnoid spaces. So frequent is this extravasation that one is inclined to think that the vessels of the brain, especially the veins, have open communication with these spaces. But since the arachnoid spaces are always free from blood, and since complete injections with India ink made by the contraction of the heart in live embryos do not form extravasations, it must be concluded that the vessels are closed in life. A similar communication has been demonstrated by Key and Retzius ${ }^{1}$ in the adult brain by injecting Prussian blue into the arachnoid spaces. Frequently the fluid passes over into the sinuses through the Pacchionian bodies, showing that here again the communication is easily established. This question will be taken up again in the description of the specimens.

I shall first describe the blood-vessels of the brains of eight embryos of the third month, which had been injected, then take them up in regular order, beginning with a reconstructed specimen of the fourth week. At this point I wish to express my great obligations to $\mathrm{Mr}$. Brödel for much of this valuable material. He has an exceptional opportunity to obtain many fresh specimens which can be injected, and I sincerely hope that physicians will continue to send him all the embryos they obtain, for Mr. Brödel makes the greatest possible use of them.

\section{INJECTIONS.}

Unfortunatley there is a tendency for the Prussian blue which has been injected to extravasate over the surface of the brain, interfering

${ }^{1}$ Key and Retzius: Studien in der Anatomie des Nervensystems und des Bindegewebes. Stockholm, 1875, p. 218. 
very much with the sharpness of the arterioles and.making it impossible to define the veins, or embryonic sinuses. So constant is this extravasation in position and degree that it often seems as if the arachnoid spaces communicate freely with the veins, but, as will be shown presently, this is not the case.

In the smallest specimen (No. 225, $46 \mathrm{~mm}$. long) the middle cerebral artery and the arteries to the mid-brain are well injected, but in no case does the injection extend into the brain substance. The arachnoid spaces are filled evenly with the blue injecting fluid, but there is none within the ventricles. Since the fluid does not reach the capillaries, it is evident that the extravasation took place from the arterioles, and this seems to be the case, for the arterioles are easily torn at the point they enter the brain substance. In the early stages the brain is attached only slightly to the embryonic pia mater, and it is practically impossible to remove the brain with its pia mater intact, as can be done in older embryos or in the adult. At the point the vessels leave the pia mater to enter the brain substance the blood-vessels have but a single endothelial wall, and it is here that the rupture and extravasation take place when these arteries are injected.

In an embryo a little older, No. 237, Fig. 1, the injection of the artery is practically perfect, and I have therefore given a drawing of it. The brain was peeled out with its pia mater only with difficulty and over the region of the lateral cerebral fissure (Sylvius) some of the vessels separated and remained attached to the dura. This portion was drawn inverted and redrawn upon the brain, and the point at which the main trunks are torn off is indicated in the drawing in the region of the island. The injection is practically a complete arterial injection with but little extravasation into the arachndid and none into the ventricles. An extravasation is over the region of the island, on both sịdes, and to a slight extent over the mid-brain on one side. The arteries divide and subdivide in regular fashion until the terminal branches are reached, when they turn at right angles to enter the brain substance. There are from five to ten of these cortical arteries to each square millimeter of brain surface. Around some of them there is some extravasation of Prussian blue, indicating the way the blue enters the arachnoid spaces.

Over the surface of the brain of an embryo $65 \mathrm{~mm}$. long (No. 234 $4^{\mathrm{b}}$ ) there are numerous blue spots, about one to each square millimeter. Where the spots are larger there is a tendency for them to run together, but in general the brain is only spotted rather than being covered evenly with an extravasation. There is no extravasation in the ventricle. In another brain of about the same age (No. $235,59 \mathrm{~mm}$. long) the ex- 
travasation is complete, filling all the arachnoid spaces and the whole ventricle. After the extravasation was brushed off, the brain substance was still found to be spotted, showing that the extravasation penetrated the brain substance.

In an embryo of the beginning of the fourth month ( $80 \mathrm{~mm}$. long) the whole brain was evenly spotted, about one spot to each square millimeter. Another specimen of the same age and of the same general appearance (No. 234 $4^{\mathrm{a}}, 80 \mathrm{~mm}$. long) (Fig. 2) was cut into serial sections in order to study the relation of the spots to the surrounding tissues and to the cortical arteries. Around the large cortical arteries (possibly the medullary arteries) there is an extravasation which encircles the vessel as a small spherical body. There is no rupture of the vessel. It indicates that at this point the vessel is at least very pervious. There is no extravasation into the ventricle.

In specimen No. 238 (90 $\mathrm{mm}$. long) both the arteries and the veins were injected without injecting the capillaries. There was no injection of the brain substance, and there is no extravasation of the cortex nor into the ventricles. At the base of the brain and in the falx there is considerable extravasation, apparently coming from the veins. In an embryo of the same age (No. $236,92 \mathrm{~mm}$. long) the arterial injection is complete again, with the usual spots of extravasation in the cortex of the cerebral vesicle. The extravasation fills all of the arachnoid spaces as well as the cavities of the ventricle. The injection passes through the medial opening into the fourth ventricle (Majendie), and apparently the ventricles are injected through this opening from the arachnoid.

It is apparent from the description of the injected embryos that as a rule the extravasation into the arachnoid spaces takes place from the arteries as they penetrate the cortex of the brain, and that in case the veins are injected the extravasation is directly from them. This conclusion was reached in part by making corresponding injections of embryo pigs, many being constantly at my disposal. In general the extravasation is the same in the pig as it is in the human embryos. It frequently appeared, however, as if the India ink injected leaked with even greater ease from the veins and sinuses of the pig's brain. In embryos in which the heart had just stopped beating the injected fluid would first fill the jugular veins, then the sinuses, from which the arachnoid spaces filled as readily as did the capillaries.

When the arachnoid spaces were filled by injecting directly into the lateral ventricles of perfectly fresh embryos, the injected fluid would not pass over into the veins. I made this test repeatedly with live embryos from 3 to $8 \mathrm{~cm}$. long, always with the same result. It is best to inject 
ordinary India ink into the ventricle of a live embryo with a hypodermic syringe. The ink spreads at once throughout the central canal of the brain and cord and escapes through the medial opening of the fourth ventricle and fills the spaces of the arachnoid of the whole brain and cord. From the cord the ink extended for a short distance along the main trunks of the spinal nerves. In the larger embryos the ink invariably flowed freely from the mouth of the pig as soon as all of the arachnoid spaces had been filled. After hardening the specimens in formalin, razor sections showed that it had reached the mouth through the Eustachian tube. It had entered the middle ear along the trunks of the seventh and eighth nerves. In younger embryos $(5 \mathrm{~cm}$. long) the fluid came out of the mouth in only half of the tests, while in the smallest ones injected ( $3 \mathrm{~cm}$. long) it did not come out of the mouth at all.

In all of these tests the India ink or the Prussian blue should have passed over into the veins were the communications with them free. In all instances the pigs were still alive or just dead when the tests were made, for it is known that extravasations take place with the greatest of ease after the embryo has been dead for some time. While in these tests injections could be made with ease from the veins into the arachnoid spaces, but not in the opposite direction, in embryos still alive it was found that in no instance would an injection into the artery pass into the arachnoid spaces. The live embryo may be injected using its own heart to inject the India ink. If the uterus is kept warm the embryo will remain alive for an hour or longer, giving ample time. The ink is to be injected directly into the liver with a hypodermic syringe and then by means of gentle massage or by gravity it is forced into the heart, which gradually pumps it all over the body. The arteries to the brain fill slowly and the granules pass over into the veins. If at this time the embryo is cooled the heart will stop, thus giving a single injection of the arteries. If it is continued, the veins will fill through the capillaries, which confuses more or less. Yet this double injection is desired in this test, for the result is always the same: in no instance is there an extravasation into the arachnoid space. In case too great a quantity of ink is injected into the liver, it is forced directly into all of the veins of the body and then the ink granules will leave the veins and enter the arachnoid spaces. If the injection of the arteries and veins of the brain is made through the arteries, using the embryo's heart to do the pumping, all of the granules remain within the blood-vessels, showing conclusively that there are no free communications between the ressels and the arachnoid spaces. When the granules do leave the spaces by injecting them directly into the veins, we must conclude that artificial openings are 
made in their walls by the excessive pressure, no matter how careful we are in making the injection.

The delicate veins and capillaries can be injected without extravasation of the fluid in case it is done by injecting a small quantity of India ink into the liver and allowing it to run from there to the head by gravity. In this way I have often obtained beautiful specimens which are clear and sharp. This pressure, which is often not over one centimeter of water, is so small that it cannot possibly be imitated with a syringe. In fact it is similar to that produced by the embryo's heart, and with these normal pressures no extravasation takes place.

I may add that in all cases the embryos were placed at once in the strongest alcohol in order to prepare them so that they may subsequently be cleared in a one per cent solution of potassium hydrate. Specimens of this sort are beautiful and instructive; a black vascular system shows through a translucent embryo. These specimens proved to be a most valuable control in the study of the sections of the human embryos, for $I$ had them in abundance, and I also got some ideas of the variations of the blood-vessels and their general relation to the surrounding structures.

\section{Arteries.}

It has been shown during recent years that in the embryo a series of segmental arteries arise from the aorta, which in the head-end of higher vertebrates unite on their distal ends to produce the two vertebral arteriez. These in turn unite at the middle line to produce the basilar artery, as has been shown by His in his monograph on the human embryo. By this process of loop-throwing we have produced in the human embryo of four weeks two vertebral arteries which unite to form the basilar and on the anterior end join with the internal carotids. So as soon as the vertebral arteries unite to form the basilar we have marked off the circle of Willis, and considering its relation to the neural tube we can identify its branches to the brain as they arise. In the specimen four weeks old (Fig. 3) the arteries are not well marked, and it is difficult to outline the primary circle of Willis, let alone the branches arising from it. A specimen a little older has in it all of the circle of Willis with the primary arteries to the brain beautifully outlined (Fig. 4), and it is possible to follow them through the capillaries over to the veins. Were it not for the great number of variations found in the arrangement of blood-vessels it would be easy to identify most of the arteries in this specimen by considering them in relation to the cranial nerves and other structures. 
The circle of Willis is fully formed in this specimen and extends from the bifurcation of the basilar artery to the anterior communicating. At the point the carotid enters the circle there is a short ophthalmic which is also present in the embryo of the fourth week (No. 2), and is shown in No. 74, Fig. 5. Throughout the region of the brain branches rise at quite regular intervals from the anterior communicating to the vertebral arteries. So regular are these branches that they might be spoken of as the segmental arteries to the brain. These are then gradually shifted, some becoming enlarged and others disappear.

The anterior and middle cerebral arteries (Fig. 4) arise as a common stem and form a main branch encircling the optic stalk from which small branches pass on the lateral side of the cerebral vesicle while the main stem continues to the front of the brain and communicates with its fellow on the opposite side immediately behind the olfactory pit. It is easy to imagine the anterior cerebral pushed into place when the cerebral vesicle protrudes over it in every direction. In embryo No. 74 (Fig. 5) the middle cerebral is much better marked, while the anterior cerebral cannot be followed to its end. In embryo No. 145 (Figs. 6-8) the adult form of these two vessels is well given. Numerous radiating branches mark the middle cerebral over the embryonic island (Fig. 6) and the anterior cerebral extends to the mesial side of the hemisphere as it does in the adult (Fig. 7). The anterior cerebral artery is pictured by His in his last great monograph on the brain ${ }^{2}$ in an embryo ${ }^{8}$ of about the same age as my embryo No. 145. This illustration is from a sagittal series like the one from which my Figs. 6-8 were reconstructed. In His' paper this vessel is called "die vorder Bogenvene die das Blut aus dem vordern Abschnitte der Hemisphärenwand sammelt." " When the direction of this vessel is considered, and especially when it is reconstructed, it is easily shown that His was in error in calling it a vein.

The anterior choroidal artery is next in order, for it also arises from the carotid artery and its destination, the choroid plexus, is well marked in young embryos. In Fig. 4, the artery which takes this position is intimately associated with the middle cerebral and lies between the cerebral hemisphere and the optic thalamus. It may be that what I have termed the anterior choroidal is in reality the middle cerebral, and that the artery more dorsalwards is in reality the choroidal, for it is well known that arteries often shift a great deal in young embryos. Not

${ }^{2}$ His: Die Entwicklung des menschl. Gehirns. Leipzig, 1904.

${ }^{8}$ Page 79, Fig. 51.

${ }^{4}$ P. 125 
until their walls are fairly well developed are the arteries well fixed. The arrangement shown in Fig. 4 is again present in embryo No. 74, Fig. 5, and here the choroid plexus is well developed. In an older embryo, Fig. 8, the anterior choroidal artery is well marked, and it arises farther back,--from the posterior communicating artery. For this reason I often thought that the more dorsal artery in Fig. 4 represented the choroidal, and only in a much later stage than that shown in Fig. 8 is the anterior choroidal shifted from the posterior communicating to the carotid. To test this question further I examined numerous transparent pigs of corresponding stages in which the arteries only had been injected, and in all cases the anterior choroidal arose in common with the middle cerebral, and after this I was strongly inclined to consider the origin of the anterior choroidal from the posterior communicating in Fig. 8 as a variation.

The posterior cerebral artery is relatively late to develop, and in early embryos its place of origin is taken by a number of large branches to the mid-brain. This is very marked in Figs. 1 , and 4 to 8 . In the large embryo (Fig. 1) the vessels have been injected and in drawing it the cerebrum was pulled forward to show the large artery to the midbrain. There is also a small posterior cerebral artery present showing that for a long time the artery to the mid-brain is much more prominent than the posterior cerebral. In the adult the posterior cerebral arteries mark the terminations of the basilar and lie immediately in front of the third and fourth cranial nerves. The arteries which fulfill these requirements supply the dorsal portion of the mid-brain, corresponding to the posterior quadrigeminal body in the adult brain. But in the adult the posterior cerebral artery, in addition to its main branches to the cerebrum, supplies much more than this, for it also sends branches to the crus, posterior part of the thalamus walls of the third ventricle, as well as elsewhere. In fact, all of the branches together arising from the circle of Willis between the third and fourth nerves behind and the origin of the middle cerebral in front (compare Figs. 4 and 9) must become united to produce the posterior cerebral artery. The region supplied by these numerous branches in the embryo is supplied by the posterior cerebral in the adult, and in its development these branches must be gradually drawn together into one stem to produce the final condition. And this is to be expected. It is only after the cerebrum makes its appearance and reaches the great prominence it does in man that the condition found in the lower vertebrates is overshadowed. At a relatively late stage, later than the one shown in Fig. 1, all of these arteries arise from a single trunk. In this there are still two main trunks which must unite subsequently to form the posterior cerebral. 
The posterior communicating branch must be formed by shifting nearly all of its branches, as shown in Fig. 4, back to the third and fourth nerves to produce the posterior cerebral artery, while the cerebral hemisphere is growing over the thalamus and mid-brain. Or by a series of arches, as indicated in Fig. 4, the arteries to the more dorsal portions of the thalamus and mid-brain, as well as to the structures which wander into this region, are gradually transferred towards the basilar, leaving the small branches of the posterior communicating to supply the immediate neighborhood, as it does in the adult. At any rate the large vessel arising from the posterior communicating in Fig. 1 arises from the posterior cerebral, probably as the postero-lateral set, in the adult. The question is further complicated by variations, which are quite numerous, the most common variation of the posterior cerebral being in its origin, which is transferred from the basilar to the internal carotid. I have also found all kinds of combinations of this artery with neighboring arteries in the embryo pig, which $I$ interpret in part as transformation stages. Furthermore, it may be possible that shifting of arteries takes place until the individual is fully grown, for Bean ${ }^{\circ}$ has shown recently that the branches of the subclavian artery of the infant differs from those of the adult.

The branches from the basilar and vertebral arteries are more easily followed, for in this region there is less shifting, and the landmarks prove to be of more value. In the upper part of the mid-brain there is a cluster of branches which are destined to become the superior cerebellar arteries (Fig. 4). This group is reduced to a single artery in Figs. 5 and 6, where it is just behind the isthmus. The next group in Fig. 4 is the transverse pontine between the superior cerebellar and the otic vesicle. Then the anterior cerebellar between the seventh and eighth nerves near the otic vesicle. Finally, the group which perforates the root of the twelfth nerve is destined to form the posterior inferior cerebellar. This branch is also shown in Fig. 1. Between this and the otic vesicle there are a couple of branches, shown in Fig. 4, the fate of which is uncertain.

\section{Verns.}

While the arteries of the brain undergo many changes in their development, their history is relatively simple when compared with the gyra-

s According to Windle (Journal of Anatomy and Physiology, XXII, 1888), this variation occurred 28 times in 400 , or in 7 per cent of the cases.

${ }^{8}$ Bean: American Journal of Anatomy, Vol. 4. 
tions the veins undergo. The subject is, however, simplified to a great extent by the excellent studies of Hochstetter and his pupils, Salzer, and Groszer and Brezina, who have unraveled many of the tangles of the anterior cardinal vein while it is being transformed into the brain sinuses. The study of the development of the veins of the head of the guinea-pig by Salzer ${ }^{7}$ is especially of value to me, for it takes up a number of points which would be difficult to interpret properly from my material.

It is generally believed since the time of Luschka ${ }^{8}$ that the blood from the veins of the brain leaves the embryonic skull through a foramen in front of the temporal bone-the foramen jugulare spurium-and empties into the external jugular vein. A secondary communication is formed with the internal jugular vein, which in man and in monkeys is the only outlet of the brain sinuses, both communications remaining open to a greater or less degree in many vertebrates. Luschka also found a human skull with a foramen jugulare spurium present between the temporal bone and the glenoid fossa. This opening is referred to frequently in the various text-books on anatomy, and it is explained by stating that it is the remains of a channel through which the blood poured in the fœetus. This explanation may be correct as far as it goes, but when it is asserted that the brain sinuses at first communicate with the external jugular vein through the foramen spurium and later with the internal jugular vein, a conclusion is drawn which the facts do not warrant. Although Salzer showed conclusively that the internal jugular vein receives all the blood from the brain from the very earliest stage, and that the connection with the external jugular is of much later formation, Luschka's statement is still retained in the text-books. ${ }^{10}$ While Salzer corrected the erroneous interpretation of Luschka, he also discovered that in the embryo the veins first leave the embryonic skull through a canal near the seventh nerve, and then emptied into the internal jugular vein. All this takes place long before there is a trace of an external jugular vein present, so the idea of Luschka that the external jugular vein is the primary vein for the blood from the brain is untenable, and should be removed from the text-books as soon as possible.

Salzer's work shows that the anterior cardinal veins of mammals are placed on either side of the chorda ventral to the brain between the

'Salzer: Morph. Jahrbuch, XXIII, 1895.

${ }^{8}$ Luschka: Denkschriften der Wiener Akademie, XX, 1862.

- See for instance Cunningham's Anatomy, p. 116.

${ }^{10}$ Cunningham's Anatomy, Figs. 603 to 606 . 
roots of the cranial veins. They soon begin to shift lateralwards, and by a process of sprouts encircle the cranial nerves successively and soon come to lie to the lateral sides of the nerves. In other words, the nerve trunks have wandered through the veins and changed positions with them. This all takes place without interrupting the circulation through the vein. In Fig. 3 the vein is shown partly wandered out, the otic vesicle, seventh and ninth nerves now being on the medial side of the vein. A number of sprouts encircles the tenth nerve, which in Fig. 9 is also on the medial side of the vein. Finally the fifth nerve wanders through the vein. In Fig. 13 this has taken place in part, and in Fig. 11 the change in position is complete. What $I$ have here given in rapid order comprises the results found by Salzer in the guinea-pig, and I repeat it only to illustrate his point with my figures. Now Salzer calls the vein which lies to the medial side of the nerves the anterior cardinal vein, and that portion which moves to the lateral side of the nerves the vena capatis lateralis. ${ }^{11}$ After the vein crosses the twelfth nerve passing to the heart he calls it the internal jugular. These terms I shall retain, for they are most useful in the description of the fate of the anterior cardinal vein. So finder wir, says Salzer (l. c., p. 248), bei den untersuchten Saügern sehr schön übereinstimmende Verhältnisse in Bezug auf die erste Entwicklung der Venen des Kopfes. Ueberall wird die ursprünglich medial von den Kopfnerven gelegene Vene durch ein Gefäsz ersetzt, das eine laterale Lage den Nerven gegenüber einnimmt. Diese Lageveränderung geht durch Inselbildung vor sich, und zwar bilden sich derartige Inseln zuerst um Acustico-facialis, fast zu gleicher Zeit auch um den Vagus herum, dann erst erfolgt die Verlagerung der Venenbahn dem Hypoglossus gegenüber; dem Trigeminus gegenüber behält die Vena verhältnismaszig lange ihre ursprüngliche Lage bei. Ist das knorpelige Skelet angelegt so verlässt das Blut der vorderen Hirnabschnitte gemeinsam mit dem Facialis die Schädelhöhle, während das Blut des Hinter- und Nachhirns von einer Vene gesammelt wird, die durch das Foramen jugulare an der lateralen Seite des Vagus nach auszen zieht; hier verbinden sich beide Gefäsze zur Vena jugularis interna. Bald jedoch obliterirt nach Ausbildung einer Anastomose dorsalwärts vom Gehörorgan die neben dem Facialis austretende Vene, so dass die neben dem Vagus austretende Vene die einzige abführende Blutbahn des Schädels darstellt. An dieses Verhalten schlieszen sich die nun sekundär auftretenden Verbindungen der Gefäsze des Schädelinneren theils mit den Gesichtsvenen, theils mit den Venen des Rück-

${ }^{11}$ His (Entwickl. des menschl. Gehirns) calls this vein Basalvene. 
enmarkes an. Dabei geht die Bahn durch das Foramen jugulare entweder vollständig oder zum Theil zu Grunde. Die bei den meisten Saügern auftretende sekundäre Verbindung ist die, welche das Foramen jugulare spurium zum Austritte benutzt, doch giebt es auch Thierformen, z. B. die Katze, bei denen ein solches gar nicht zur Ausbildung kommt, obwohl die Vena jugularis interna fast vollständig zu Grunde gegangen ist. Hier treten eben die sekundären Verbindungen, welche die Orbital- und Nachhirnvenen eingehen, für diese Gefasze ein. Mithin kann man wohl behaupten, dass die Vena jugularis interna als Fortsetzung des Sinus transversus, wie sie beim Menschen und beim Affen am schönsten ausgebildet ist, ein primitiveres Verhalten darstellt, bei welchen die Vena jugularis externa die hauptsächliche, wenn nicht die einzige abführende Bahn des Schädelinneren darstellt.

It is apparent from the above that the beginning of the internal jugular vein is marked by the twelfth nerve crossing the anterior cardinal vein and that it extends to the lateral sinus through a number of sprouts behind the otic vesicle (Fig. 13). The vena capatis lateralis is that portion of the anterior cardinal vein which wanders to the lateral side of the cranial nerves and extends from the twelfth to the fifth nerve. The portion of the anterior cardinal vein which lies medial to the fifth nerve retains that position throughout its development and marks the cavernous sinus (Fig. 10). Into the embryonic cavernous sinus there empties the ophthalmic and anterior cerebral veins. The latter soon extend to the embryonic superior sagittal sinus. Between the fifth and rth nerves a vein extends to the region of the cerebellum, the vena cerebralis media (Figs. 9, 10 and 13), and behind the otic vesicle there extends through the embryonic jugular foramen the vena cerebralis posterior (also shown in Fig. 11).

We have, therefore, in the embryos of the second month an arrangement of the veins in the head similar to that found in the reptiles as shown by Groszer and Brezina, ${ }^{12}$ and I shall employ the nomenclature of these authors. The anterior cardinal vein shifts lateralwards and by the end of the first month is partly lateral to the otic vesicle as shown in Fig. 3. The process is shown more advanced in Fig. 9, and is complete in Fig. 13. The condition shown in Fig. 13 is that which is permanent in selachians. Now the reptilian stage is entered. From the lateral vein-the vena capatis lateralis--three veins extend into the head and encircle the brain. The first-the vena cerebralis anterior (shown well in Fig. 10) - passes up and over the cerebral vesicle, $i$. e.,

${ }^{12}$ Groszer and Brezina: Morph. Jahrb., XXIII, 1895. 
the region of the island. The second-the vena cerebralis media (Figs. 9,10 and 13)-arises at the anterior juncture of the vena capatis lateralis with the anterior cardinal vein between the fifth and seventh nerves. The third-the vena cerebralis posterior-arises from the posterior part of the vena capatis lateralis with the internal jugular behind the otic vesicle and enters the embryonic skull through the jugular foramen (Fig. 12), and ultimately becomes the transverse sinus. From this simple reptilian stage the mammalian is formed, and in man but little must be added to, and but little subtracted from, the general plan.

The anterior end of the anterior cardinal vein remains in large part on the medial side of the fifth nerve in the human embryo and is ultimately transformed into the cavernous sinus. From the earliest stages the ophthalmic vein enters this sinus as is shown in all of the embryos studied. Although I have no evidence regarding the development of intercavernous sinus, it is easy to understand its development by branches from the cavernous sinus growing to encircle the hypophysis, and then to unite, thus forming a plexus around it. So also by an extension of the cavernous sinus forwards the spheno-parietal sinus must be formed. In the early embryos the anterior cardinal vein or the portion which forms the cavernous sinus is extended forward to form the vena cerebralis anterior, which ends in the bilateral superior sagittal sinus as shown in Fig. 3. With this the veins from the region of the island communicate as shown in Fig. 10, the basal portions of which are evidently retained to form the middle cerebral (superficial Sylvian) vein. So also the superior sagittal sinus, the superior and inferior petrosal sinuses and the vena capatis lateralis are directly continuous with the cavernous sinus from their beginning.

I have spoken enough about the vena capatis lateralis above, and wish cnly to add its relation to the permanent brain sinuses in man at this point. It may be defined as that portion of the anterior cardinal vein which is transferred to the lateral sides of the cranial nerves extending in the human embryo from the fifth to the twelfth cranial nerves, being directly continuous in front with the anterior cardinal vein, or better the cavernous sinus, and behind with the internal jugular vein. This vein is clearly outside of the skull, leaving it between the fifth and seventh nerves (Fig. 12), and then communicating with the internal jugular. It is this vein which Kölliker believed to be the external jugular, and apparently confirmed Luschka's notion regarding the relation of the external jugular vein to the brain sinuses. It certainly does leave the skull along the root of the seventh nerve, a line in common with the socalled foramen jugulare spurium, but it disappears long before 
external jugular vein is formed, as shown by Salzer. The vena capatis lateralis is fully developed during the fifth week, as is best shown in Fig. 13. In this embryo it is irregular in shape, ending in a lakelet behind, a condition which may also be due to the way the blood accumulated in this vein just before the death of the embryo. In Fig. 10, which is from an embryo in which these veins were gorged with blood, the lakelet is not present. Soon the vena capatis disappears, and veins more dorsalwards carry blood from the brain, as shown in Fig. 11.

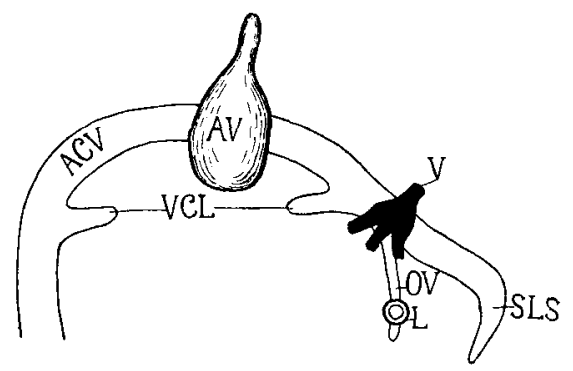

FIG, 14.

Fua. 14. Diagram of the veins of the head of an embryo four weeks old. $A C V$, anterior cardinal vein; $V C L$, vena capatis lateralis; $S L S$, superior sagittal sinus; $A V$, auditory vesicle; $V$, fifth nerve; $L$, eye.

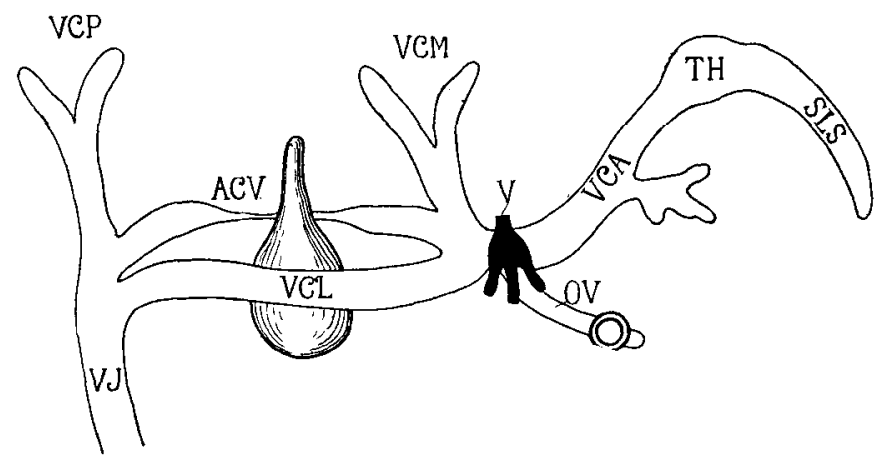

FIG, 15.

FIG. 15. Diagram of the veins of the head during the fifth week. VCP, vena cerebralis posterior; VCM, vena cerebralis media; VCA, vena cerebralis anterior; $T H$, torcular Herophili ; $O V$, ophthalmic veins; $V J$, jugular vein.

When the vena capatis is well developed it sends from its two extremities two main veins to encircle the brain and to collect its blood. The first of them, the vena cerebralis media, arises at the point of juncture between the vena capatis lateralis and the cavernous sinus and extends between the fifth and seventh nerves towards the region of the cerebellum. 
The vena cerebralis posterior arises from the vena capatis lateralis more dorsalwards, at its juncture with the vena jugularis interna, and encircles the hind-brain in the region of the twelfth nerve. These two veins are well shown in Figs. 9 and 13.

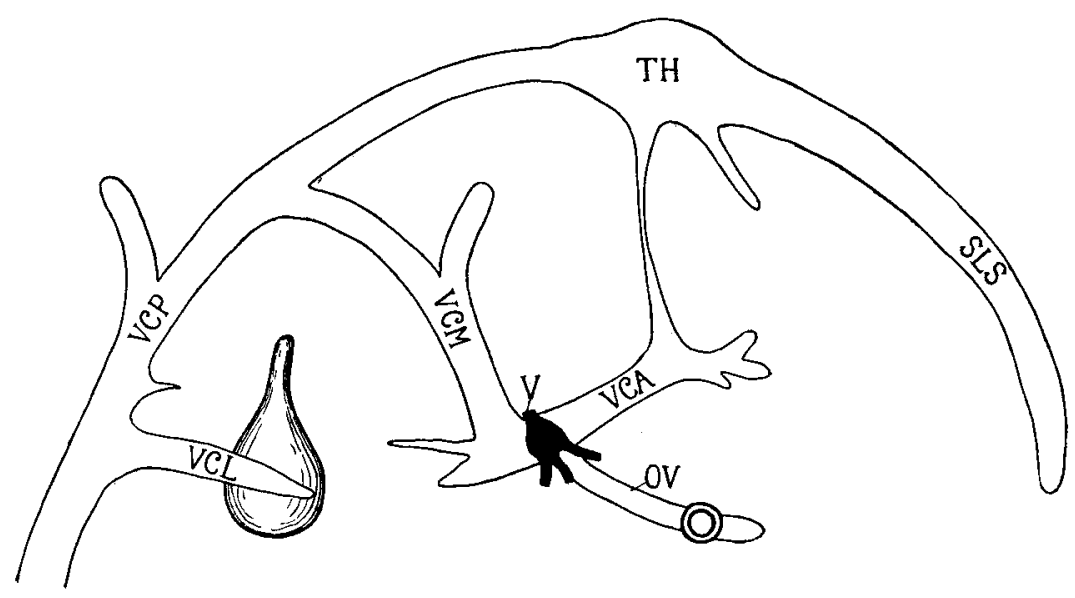

FIG. 16.

FIG. 16. Diagram of the veins of the head at the beginning of the third month. Lettering as before.

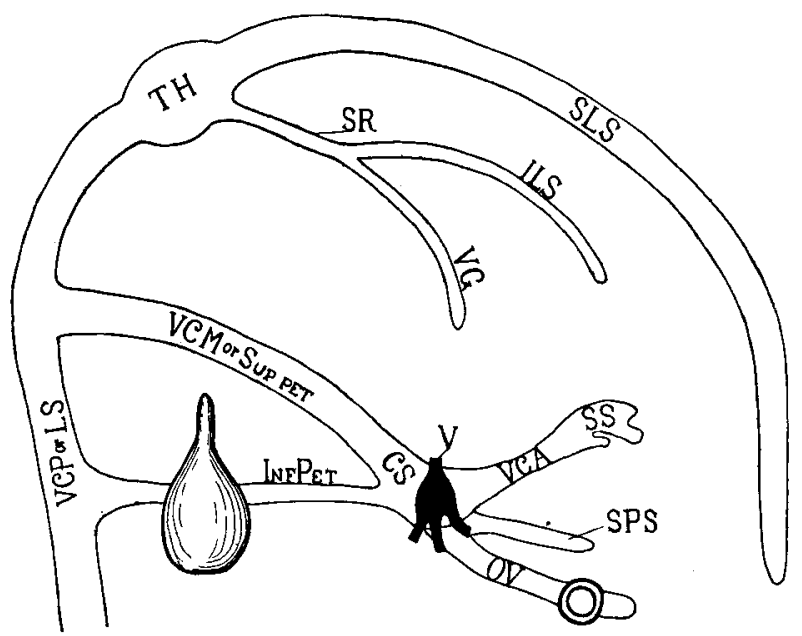

FIG. 17.

FIG. 1\%. Diagram of the veins of the brain of an older foetus. Lettering as before. LS, transverse sinus; $S R$, sinus rectus; $I L S$, Inferior sagittal sinus; $V Q$, great cerebral vein (Galen); CS, cavernous sinus; SS, middle cerebral vein (Sylvian); SPS, spheno-parietal sinus; Sup. Pet., superior petrosal; Inf. Pct., inferior petrosal sinus. 
The superior sagittal sinus is formed by an accumulation of small veins over the dorsal side of the cerebral vesicle (Fig. 3), which sometimes appear as a tuft (Fig. 13) and at other times as a lakelet (Fig. 9). Soon the sinuses of the two sides communicate (Fig. 10), and from now on the paired sinuses are single. At first the sinuses communicate with the anterior cardinal vein (the cavernous sinus) through the vena cerebralis anterior, and these two veins take up all of the small veins from the cerebral vesicle (Fig. 10). With the growth of the cerebrum the superior sagittal sinus is shifted downwards and its communication with the cavernous is broken. It now communicates with the vena capatis lateralis through the vena cerebralis media, a transitional form being shown in Fig. 10. With great rapidity the communication is transferred to the jugular through the vena cerebralis posterior, which leaves the skull through the jugular foramen. This stage is shown in part in Fig. 11, which is a reconstruction from a partial natural injection. However, even in this case the superior sagittal sinus must be shifted more dorsalwards, for in this embryo it still passes lateral to the otic vesicle, and therefore in this region it is outside of the skull. The same criticism can be made of Salzer's figure of the corresponding stage in the guinea-pig. ${ }^{13}$ Here also the vena capatis lateralis, as well as the first dorsal anastomosis, is lateral to the otic vesicle, and therefore cannot possibly be the permanent vein in this animal. In order to reach the permanent form, as shown in Salzer's Fig. 5, a second dorsal anastomosis must be established, and this is well begun, as Salzer's Fig. 4 shows. So in order to complete the superior sagittal and transverse sinuses a more dorsal anastomosis must be established than that shown in Fig. 11, and the indications for this are present in this figure, as well as in Fig. 10. In this latter figure the superior sagittal sinus must be transferred completely from the vena cerebralis anterior to the vena cerebralis posterior, and in so doing the vena capatis lateralis is obliterated. In case they all remained open, we would have the condition found in Tropidonotus, ${ }^{14}$ but this is not the case, as is indicated in Fig. 11. The complete condition of the superior sagittal sinus is shown in Fig. 8. Here the internal jugular communicates through the vena cerebralis posterior with the dorsal end of the superior sagittal sinus along the line of the hind-brain and mid-brain. The steps towards this are all indicated in Fig. 10. Therefore the main portion of the transverse sinus is formed directly from the vena cerebralis posterior.

${ }^{13}$ Salzer: Morph. Jahr., XIII, Taf. XVIII, Fig. 4.

${ }^{14}$ Groszer and Brezina: Morph. Jahr., XXIII, Taf. XXI. 
If now the vena cerebralis media, as shown in the human embryo, is compared with that in Tropidonotus, and in turn with that of the adult sinuses, it is seen that the vena cerebralis media is the superior petrosal sinus. They all communicate with the cavernous sinus between the fifth and seventh nerves, they lie lateral to the cranial nerves behind the fifth, and they are also medial to the otic vesicle, $i . e$., they are within the skull. This latter condition is not yet the case in Fig. 11, but is indicated in Fig. 10, and it is marked by the stub vein near the pons in Fig. 8.

The dilatation at the posterior end of the superior longitudinal sinus marks the beginning of the torcular Herophili (Fig. 8), and from it the sinus rectus extends towards the choroid plexus, where it ends in the great cerebral vein. Between the straight sinus and the superior sagittal sinus a small vein enters the falx and ends at once in a capillary plexus. This vein no doubt marks the beginning of the inferior sagittal sinus. Behind the transverse sinus (Fig. 8) there is a second venous anastomosis extending from the region of the mid-brain to the internal jugular vein, and no doubt marks the occipital sinus, which in the adult is as an anastomosing channel between the upper and lower ends of the transverse sinus. Extending forwards from the juncture of the transverse sinus with the internal jugular vein, a venous sprout is shown in Fig. 8, which passes on the outside of the skull towards the seventh nerve, and marks the remnant of the vena capatis lateralis.

In the youngest human embryos the anterior cardinal veins run on the medial side of all of the cranial nerves before the vena capatis lateralis is formed. In case the whole of the anterior cardinal vein remained permanently, that portion between the cavernous sinus and the internal jugular vein would become the inferior petrosal sinus, for they both hold the same position. But it appears that the inferior petrosal sinus is of new formation, for in none of the intermediate stages can a trace of it be found.

A résumé of the development of the sinuses of the brain from the anterior cardinal vein is given in Figs. 14 to 1\%. They explain themselves.

\section{EXPLANATION OF PLATES.}

Plate I.

Fia. 1. Surface of the brain with the arteries injected in an embryo 48 mm. long (No. 237). Enlarged 5 times; injecter by Mr. Brödel. The dorsal end of the cerebral vesicle has been drawn forward to show better the vessels of the mid-brain.

Fig. 2. Surface view of the brain of an embryo $80 \mathrm{~mm}$. long (No. 234a). Slightly enlarged from a photograph by Dr. Mellus. Over the region of the 
island the extravasation is extensive, while over the rest of the brain it is in spots along the arterioles, as they penetrate the brain.

FIG. 3. Embryo of the fourth week (No. 2). Enlarged 16 times. The external form is from nature. The structures within the head have been reconstructed; the tenth and twelfth cranial nerves and the first cervical nerve by Dr. Streeter.

FIG. 4. Brain and its arteries of embryo No. 163. Enlarged 15 times. The picture of the brain is from a wax-plate model by Dr. Lewis. The arteries are from a graphic reconstruction. The basilar artery extends throughout the length of the hind-brain and the circle of Willis throughout that of the fore-brain. The position of the cranial nerves and otic vesicle is given in Fig. 9.

\section{Plate II.}

FIG. 5. Graphic reconstruction of the head of embryo No. 75, showing the arteries and the brain. Enlarged 7 times.

FIG. 6. Graphic reconstruction of the brain and arteries of embryo No. 145. Enlarged 7 times.

FIG. 7. Same as Fig. 6. The right cerebral hemisphere has been removed, showing the anterior cerebral artery throughout its extent.

Fig. 8. Same as Fig. 7 with the choroid plexus and large veins added.

FIG. 9. Embryo No. 163. Enlarged 13 times. The surface view is from an excellent photograph, and the structures in the head are from a graphic reconstruction.

\section{Plate III.}

Fig. 10. Graphic reconstruction of the veins and brain of embryo No. 74 . Enlarged about 10 times.

FIG. 11. Graphic reconstruction of veins of the head and brain of embryo No. 144. Enlarged about 7 times.

FIG. 12. Section through the head of embryo No. 109. Enlarged 121/2 times. $H$, hypophysis; $S . O b$, superior oblique muscle; $E x . R$, lateral oblique muscle; $T r$, trapezius; $V J$, jugular vein. The cranial nerves are numbered with Roman numerals. On the side lettered the section is nearer the mouth than on the other side, showing that the vena capatis lateralis which connects with the jugular vein is on the outside of the skull.

Fig. 13. Head of embryo No. 109. Enlarged $121 / 2$ times. The form of the arm and body are from photographs. The face, brain and nerves are from a wax-plate reconstruction by Dr. Lewis. The veins are from a graphic reconstruction. The brain and face are somewhat distorted, but are given in this way to complete Fig. 5, Plate IV, in the publication of Bardeen and Lewis in vol. I of this journal. 
DEVELOPMENT OF THE BLOOD-VESSELS OF THE HUMAN BRAIN FRANKLIN P. MALL

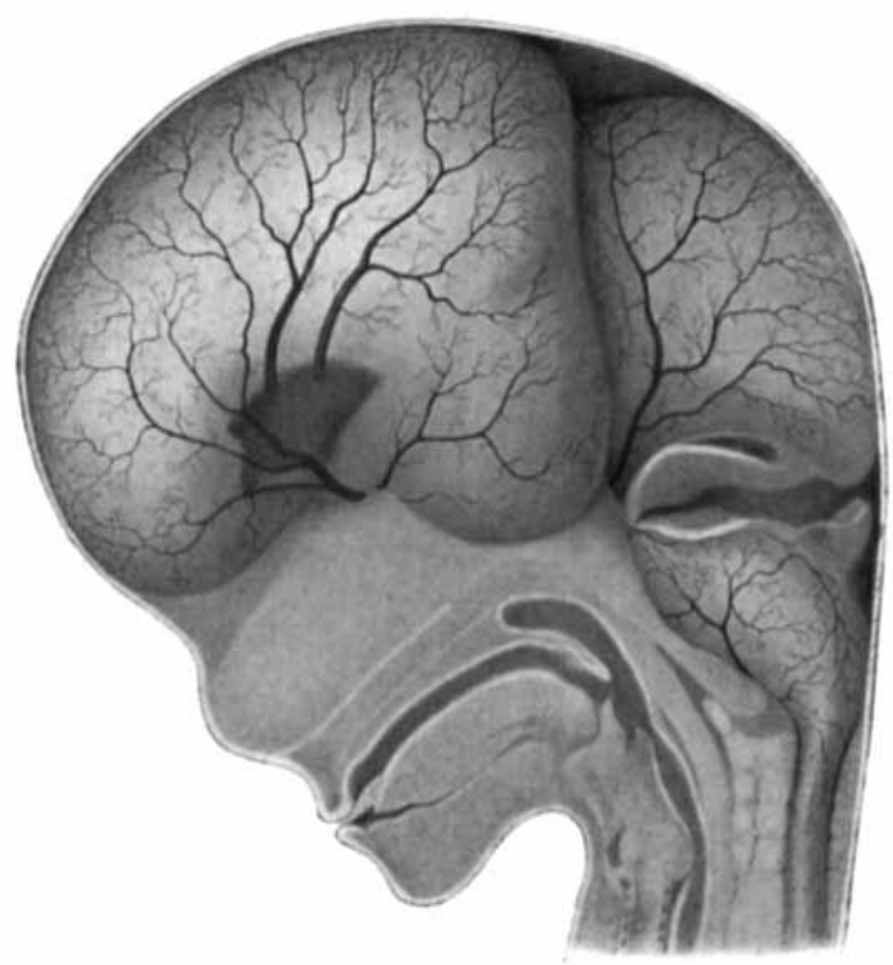

FiG. 1.

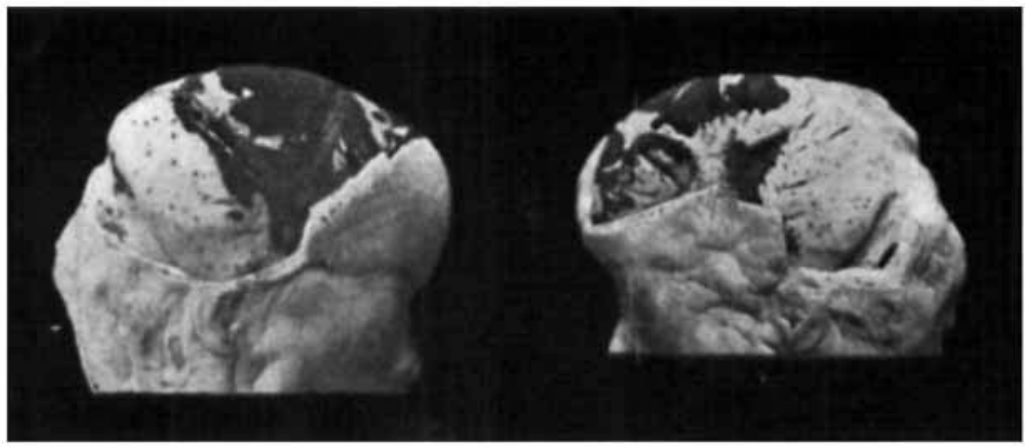

FIG. 2 . 
PLATE |

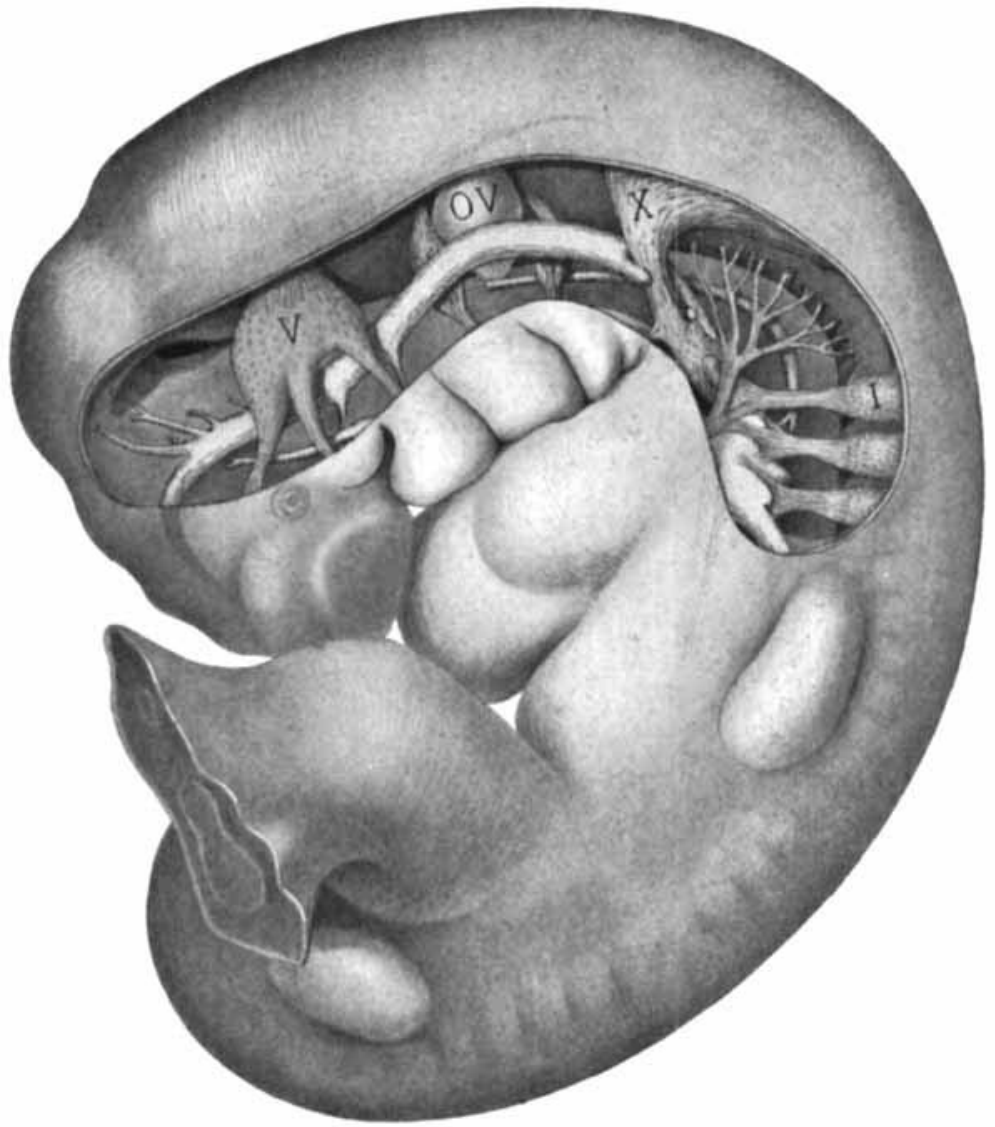

FIG. 3.

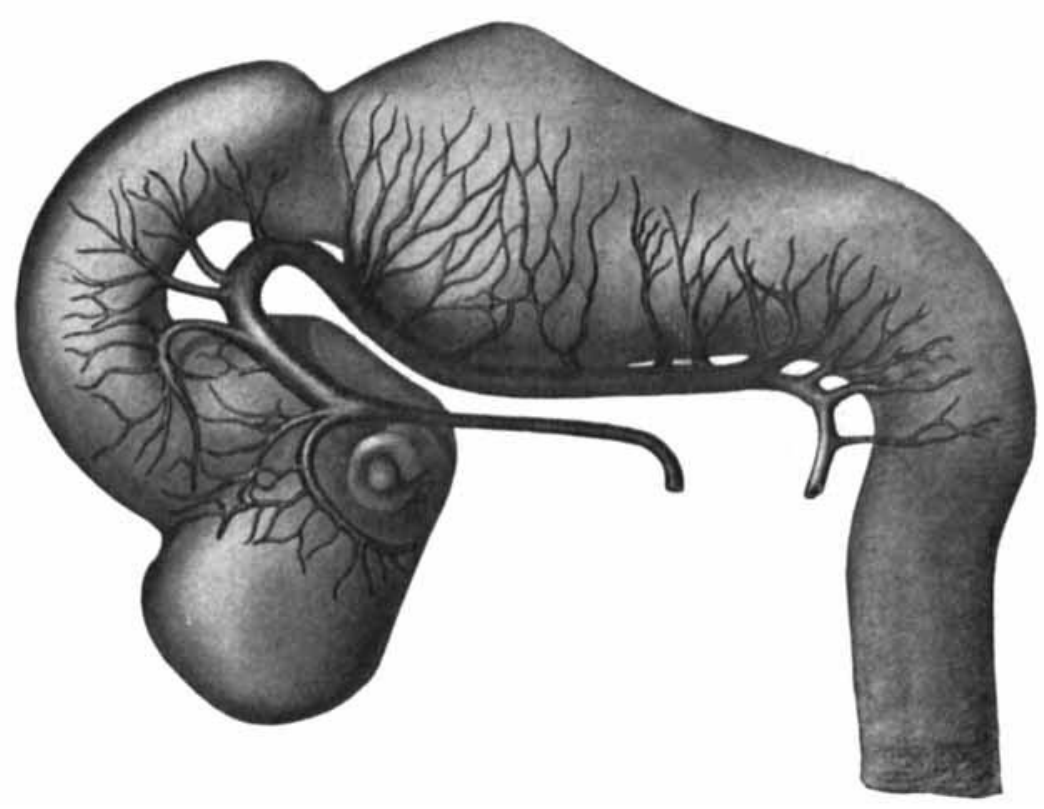

FIG. 4.

Kline, ael. 
DEVELOPMENT OF THE BLOOD-VESSELS OF THE HUMAN BRAIN FRANKLIN P. MALL

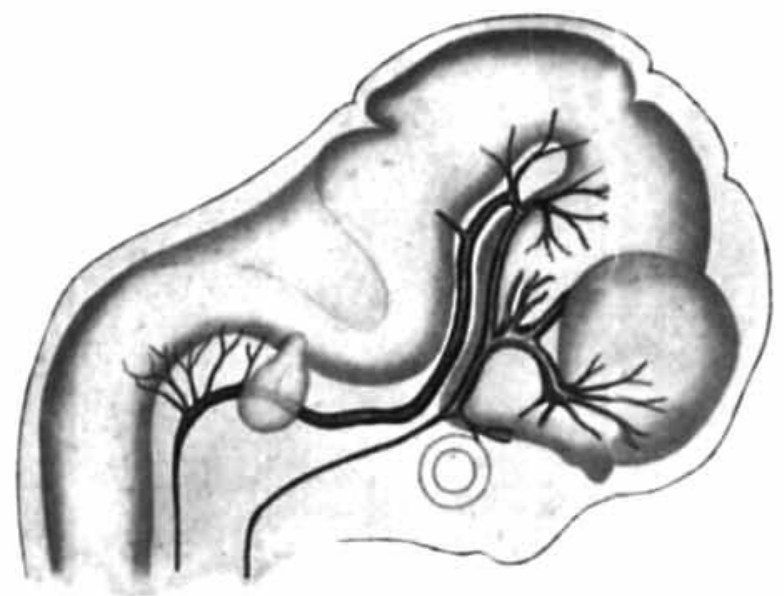

FIG. 5 .

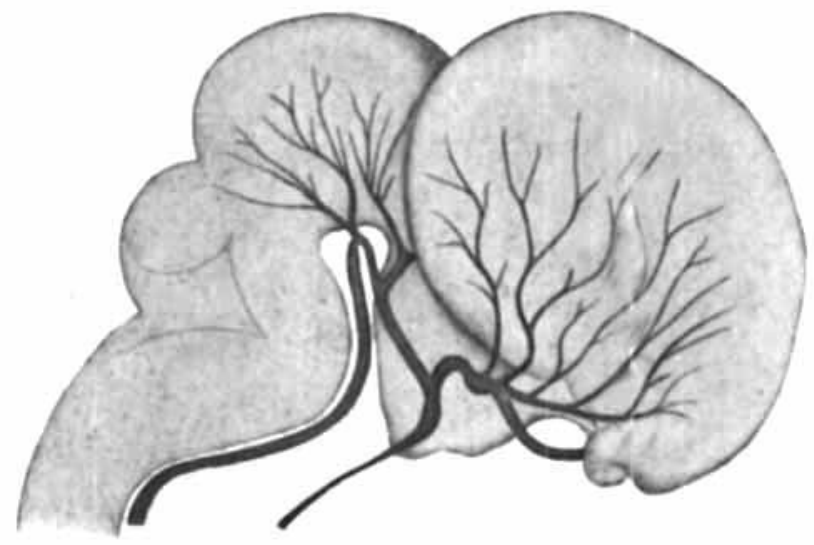

FiG. 6.

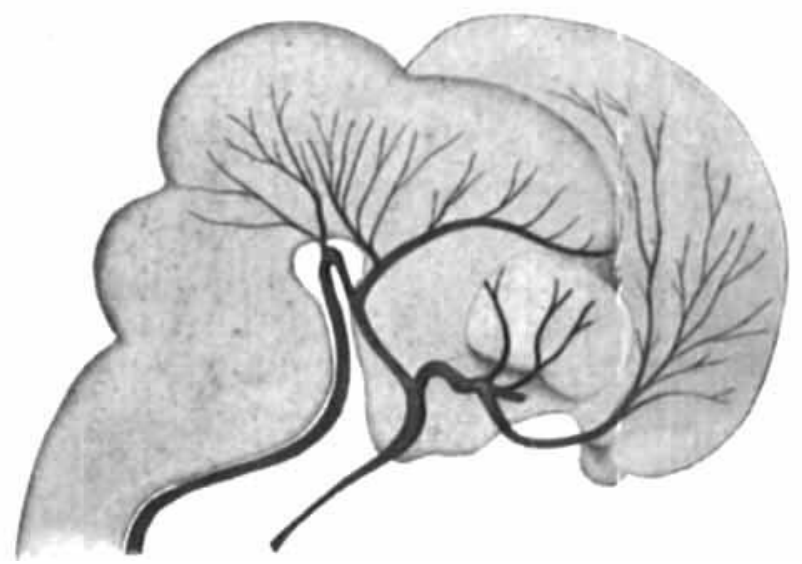

FIG. 7. 
PLATE II

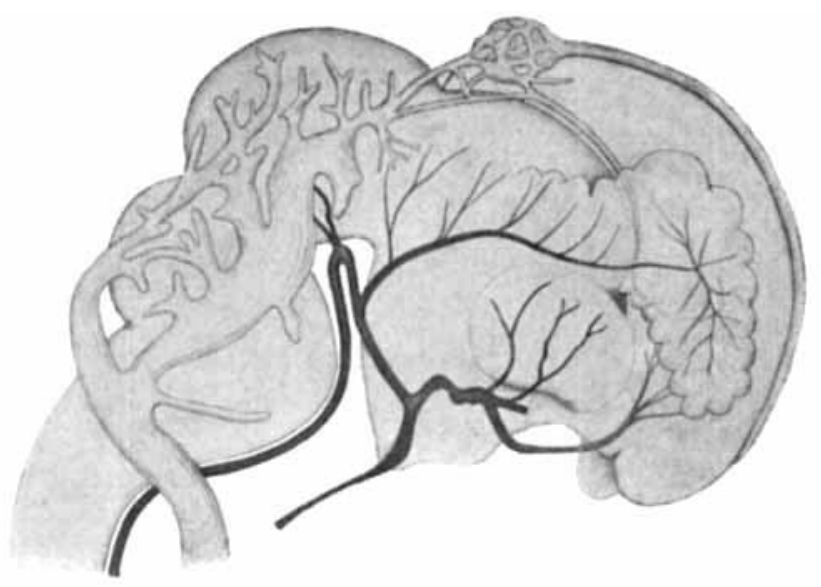

FIG. 8.

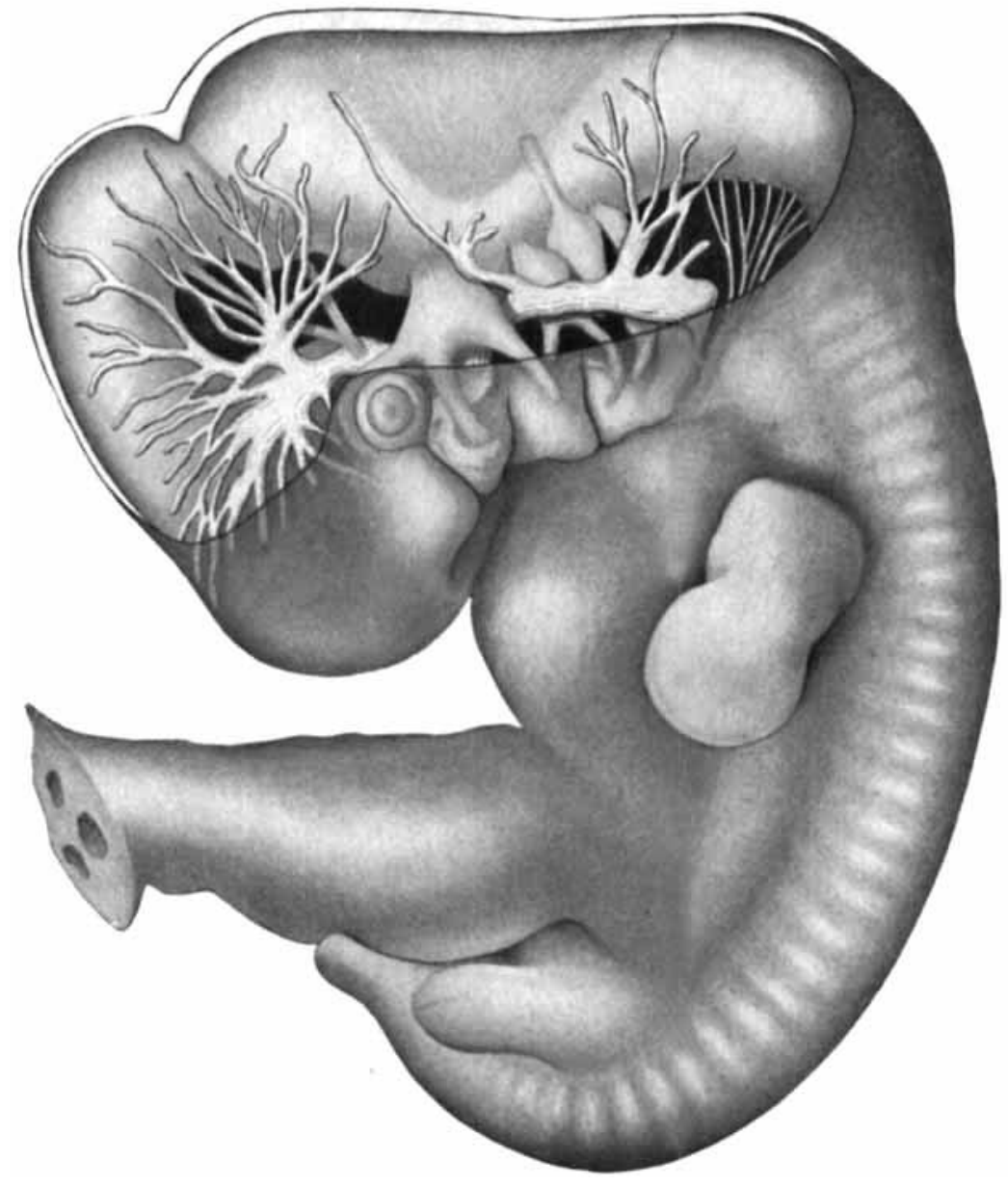

FIG. 9. 


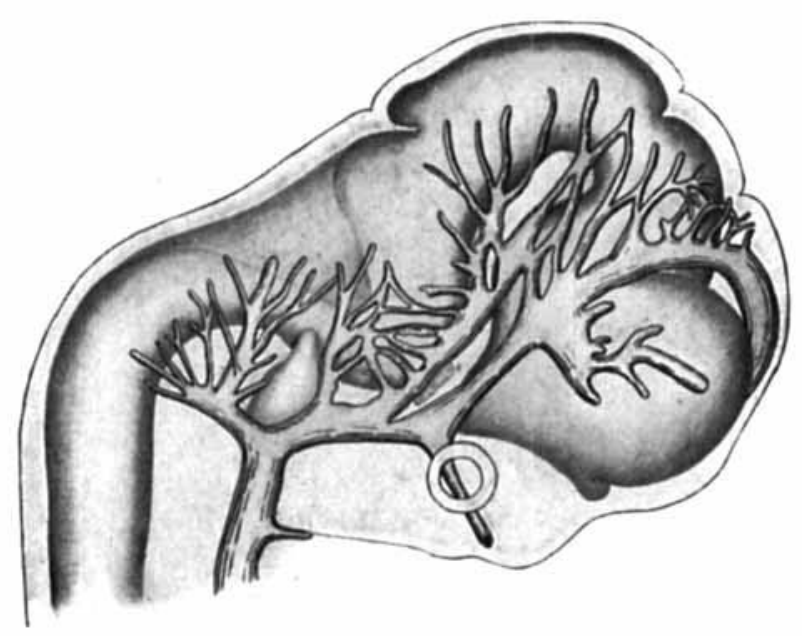

FIG. 10.

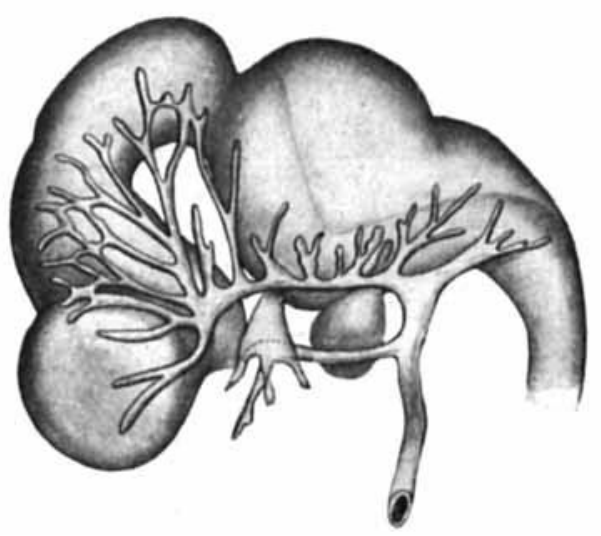

FIG. 11. 
PLATE III

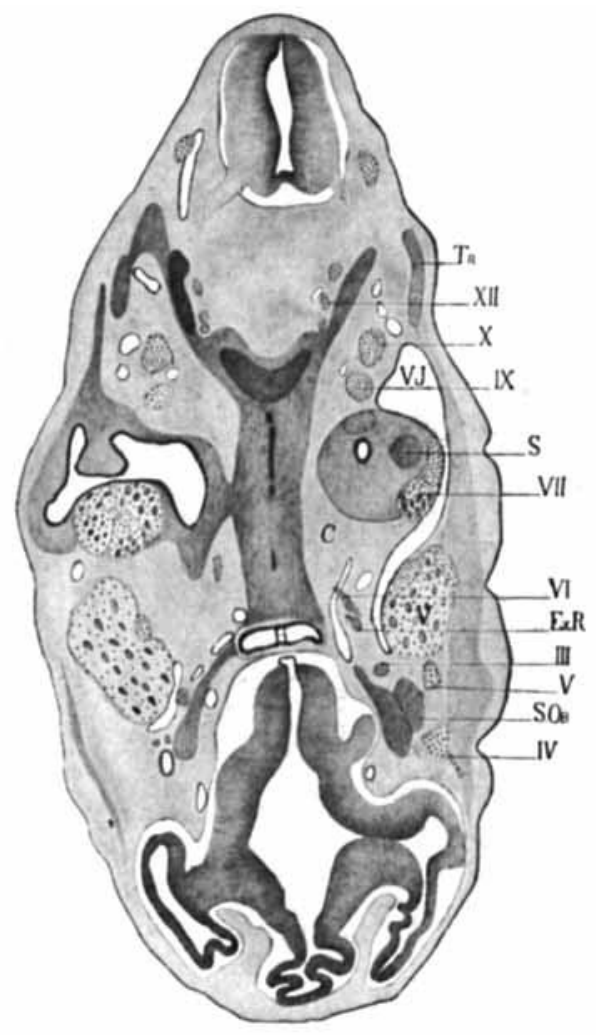

FIG. 12.

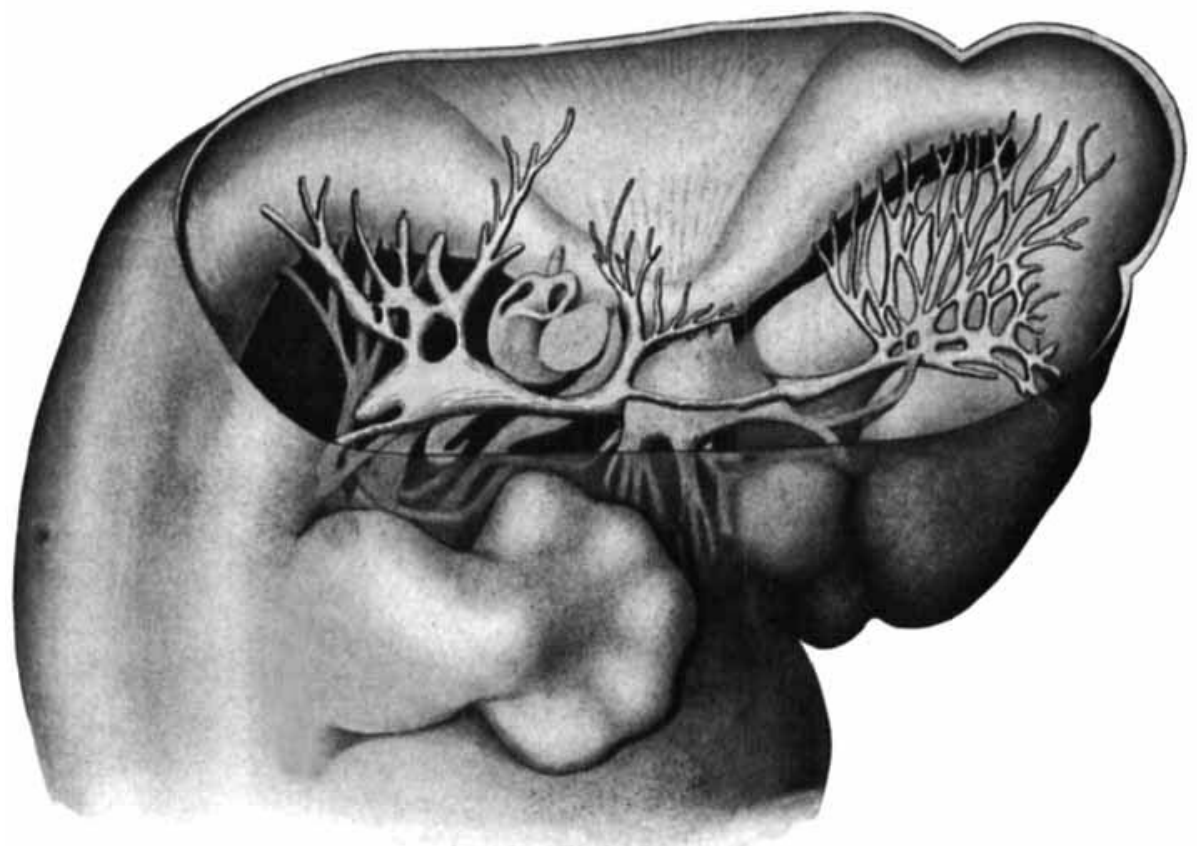

FIG. 13. 